\title{
THERMAL ANALYSIS OF LOW LAYER DENSITY MULTILAYER INSULATION TEST RESULTS
}

\author{
W.L. Johnson \\ NASA Kennedy Space Center, NE-F6 \\ Kennedy Space Center, FL, 32899, USA
}

\begin{abstract}
Investigation of the thermal performance of low layer density multilayer insulations is important for designing long-duration space exploration missions involving the storage of cryogenic propellants. Theoretical calculations show an analytical optimal layer density, as widely reported in the literature. However, the appropriate test data by which to evaluate these calculations have been only recently obtained. As part of a recent research project, NASA procured several multilayer insulation test coupons for calorimeter testing. These coupons were configured to allow for the layer density to be varied from 0.5 to 2.6 layer $/ \mathrm{mm}$. The coupon testing was completed using the cylindrical Cryostat-100 apparatus by the Cryogenics Test Laboratory at Kennedy Space Center. The results show the properties of the insulation as a function of layer density for multiple points. Overlaying these new results with data from the literature reveals a minimum layer density; however, the value is higher than predicted. Additionally, the data show that the transition region between high vacuum and no vacuum is dependent on the spacing of the reflective layers. Historically this spacing has not been taken into account as thermal performance was calculated as a function of pressure and temperature only; however the recent testing shows that the data is dependent on the Knudsen number which takes into account pressure, temperature, and layer spacing. These results aid in the understanding of the performance parameters of MLI and help to complete the body of literature on the topic.
\end{abstract}

KEYWORDS: Multilayer Insulation, Optimization

\section{INTRODUCTION}

Multilayer insulation (MLI) is the ultimate in high performance insulation. It specifically addresses all modes of heat transfer through the basic design of the system. MLI is often used inside of a vacuum shell, eliminating gas convection and minimizing gas 
conduction to the molecular scale. The reflective shields are used to minimize radiation heat transfer inversely proportional to the number of shields. Low conductivity spacers are used to prevent the metallic based reflective shields from touching and they minimize the conduction through the blanket itself. Much care is taken to design the MLI blanket such that it minimizes heat transfer in every manner including edges, seams, and installation procedure.

One variable to the design of the insulation system that has become popular over the last several years is the spacing in between the radiation shields. By increasing the spacing between shield, there is less likelihood of the shield touching and also a higher thermal resistance between the shields due to a thicker spacing. In some configurations (such as small diameter piping) the negative side effect of this spacing is that the area of each shield is greater. Other configurations where the insulation thickness is fixed would have room for less radiation shields due to the larger gap between the shields. Semi-empirical equations such as those produced by Keller [1] or Hastings [2] show that the heat flux is a function of the layer density to a power between 2 and 3, this indicates that a strong effort should be made to minimize the layer density.

Previous analysis using various published equations [1] [2] [3] [4] showed that a theoretical minimum heat flux occurred at an optimal layer density (see Figure 1) [5]. In order to prove the existence of this optimum, a series of tests were devised to test MLI at different layer densities, both at the same thickness and at the same number of layers (variable thickness). While the optimum layer density depends on the equation used and the boundary temperatures, for warm boundary temperatures of around $300 \mathrm{~K}$ and a cold boundary temperature of $77 \mathrm{~K}$, the optimum tends to lie between 0.8 and 3.0 layer $/ \mathrm{mm}$.

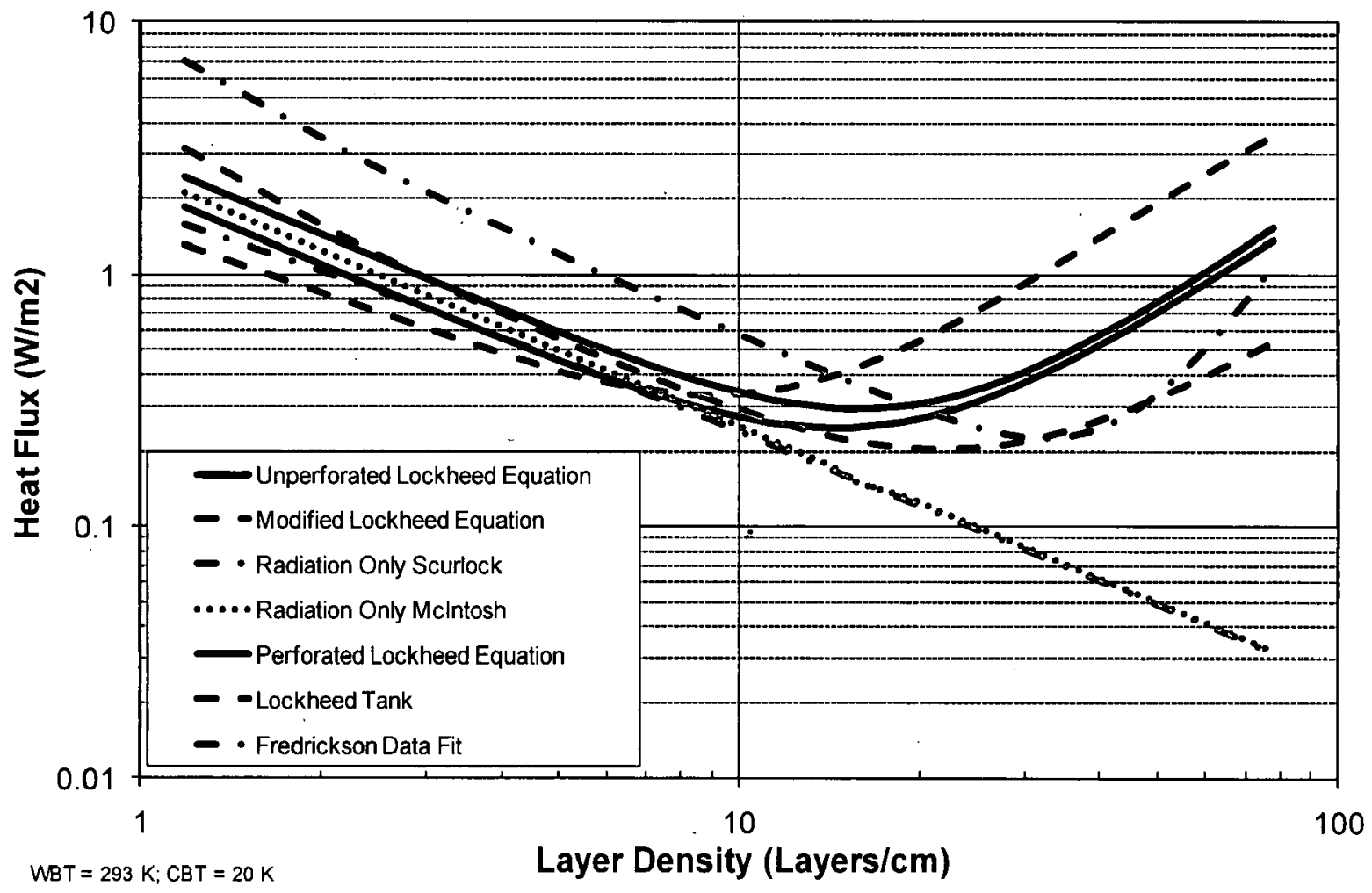

Figure 1: Heat Flux as a function of layer density for a constant thickness (25.4 mm) 
Table 1: Geometrical Parameters for Variable Layer Density Testing

\begin{tabular}{|c|c|c|c|c|c|c|}
\hline $\begin{array}{c}\text { Test } \\
\text { Series }\end{array}$ & Coupon & $\begin{array}{l}\text { Number } \\
\text { of Layers }\end{array}$ & $\begin{array}{c}\text { Layer } \\
\text { Density } \\
\text { (layer/mm) }\end{array}$ & $\begin{array}{c}\text { Thickness } \\
(\mathrm{mm})\end{array}$ & $\begin{array}{c}\text { Mean } \\
\text { Area }\left(\mathrm{m}^{2}\right)\end{array}$ & $\begin{array}{c}\text { Mass } \\
\text { Density } \\
\left(\mathrm{kg} / \mathrm{m}^{3}\right)\end{array}$ \\
\hline A138 & $\overline{\text { BATC A }}$ & 60 & 0.95 & 63.3 & 0.409 & 45 \\
\hline A139 & BATC A & 40 & 0.94 & 42.7 & 0.377 & 45 \\
\hline A140 & BATC B & 60 & 0.94 & 63.6 & 0.409 & 37 \\
\hline A141 & BATC B & 60 & 1.45 & 41.4 & 0.375 & 57 \\
\hline A142 & $\begin{array}{l}\text { Quest } \\
\text { IMLI }\end{array}$ & 20 & 0.52 & 38.7 & 0.370 & 21 \\
\hline A144 & BATC B & 60 & 2.61 & 23.0 & 0.344 & 95 \\
\hline
\end{tabular}

\section{EXPERIMENTATION}

Recent analytical exercises focused on optimizing the layer density for minimal heat transfer over a given thickness [5]. However, little to no comparable test data could be found to compare to the analytical solution. In order to produce this data, NASA procured two 60 layer MLI blankets from Ball Aerospace one fixed at 1.0 layer/mm (25 layer/in) and another that could be modified to be tested at three different layer densities: 1.0, 1.5 and 2.5 layers $/ \mathrm{mm}(25,38$, and 63 layer/in). Additionally, as a deliverable for an SBIR Phase II project, Quest provided a blanket at 0.5 layer/mm (12.5 layer/in) to NASA.

All testing was done on the Cryostat-100 guarded cylindrical calorimeter at the Cryogenics Test Laboratory [6]. Table 1 shows the geometric definitions of the test articles.

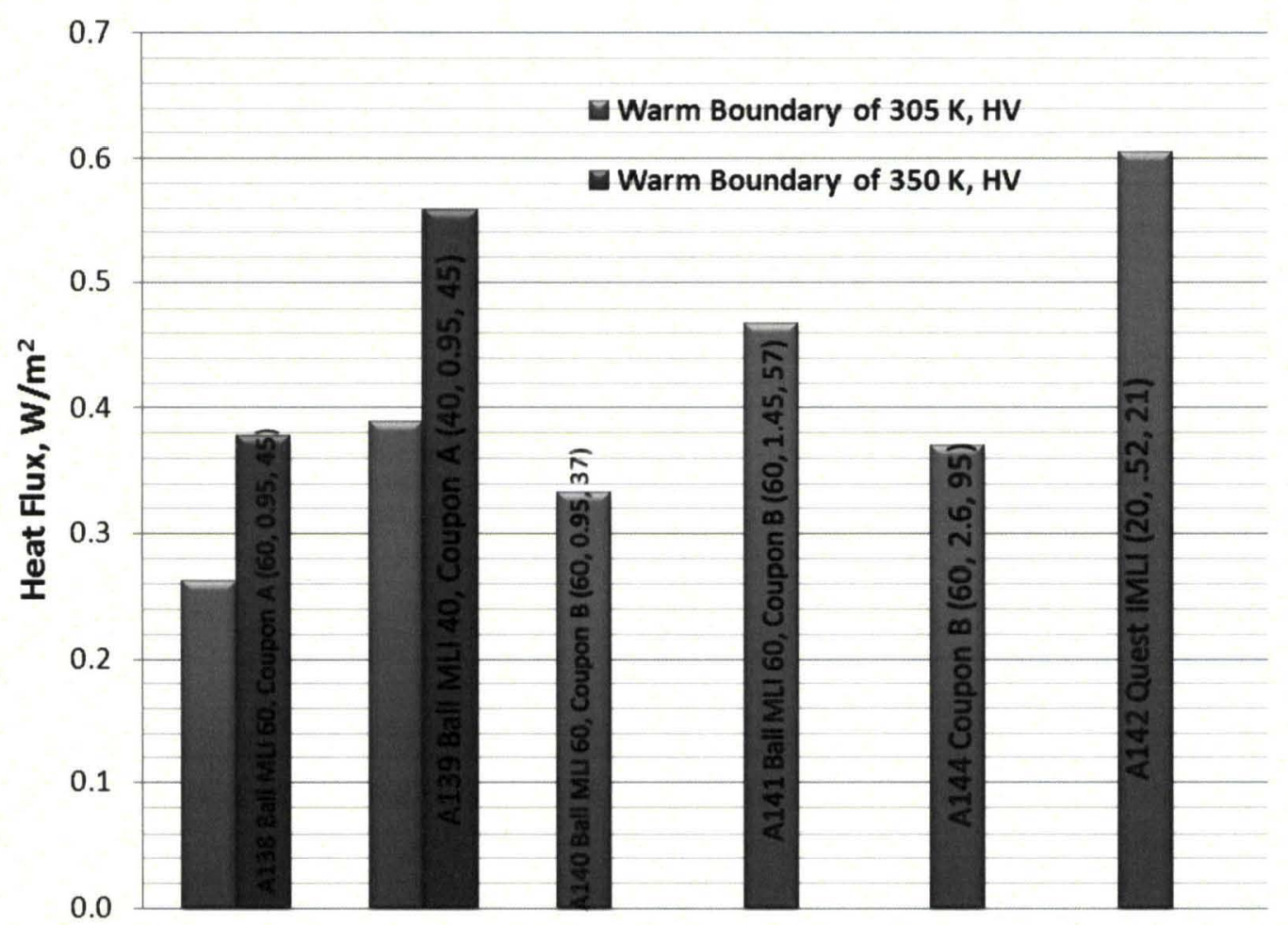

Figure 2: High Vacuum Heat Flux for Various MLI Systems.

Numbers in parenthesis represent (\# layers, layer $/ \mathrm{mm}$, and density $-\mathrm{kg} / \mathrm{m}^{3}$ ) 


\section{RESULTS AND DISCUSSION}

The heat flux (Figure 2) and thermal conductivity (Figure 3) for the insulation systems tested are shown below. While the data that is discussed in this paper is entirely at high vacuum (less than 5.0E-6 Torr), testing was also performed at degraded vacuums and is presented elsewhere [7].

Comparisons between the blankets tested yield some interesting results. Figure 3 shows that as predicted at low layer densities, the thermal conductivity decreases with increasing layer density. Figure 4 shows that this trend covers the range of layer densities tested in this case, but just outside that range, the trend reverses. Combined with data from previous flat plate calorimeter testing [1], the optimal layer density appears to be between 1.5 and 2.6 layers $/ \mathrm{mm}$. The shape suggests that the optimum is much closer to 2.6 layers/mm at boundary conditions of roughly $77 \mathrm{~K}$ and $293 \mathrm{~K}$. Mass is another important parameter in many applications of high performance insulation. Table 3 also shows the mass and the aerial density of the blanket applied to the entire surface of the calorimeter $\left(0.525 \mathrm{~m}^{2}\right.$ including both guard chambers). While the seam construction is slightly different (causing A139 to be slightly heavier, than the other two, roughly $25 \mathrm{~g} /$ layer), the overall effect is clear in that a direct product of the mass and density for each system shows a tendency towards the lower performing (but lighter) system. However, it is not clear that this product is proper for predicting direct mass effects due to increased fluid storage requirements associated with higher heat loads. It does provide an initial look at combining mass and heat load into a single parameter. Further work is required to extend the test data and analysis to a method of optimizing a MLI system for minimum mass.

Table 2 shows the calculated optimal layer densities from the equations derived by Johnson [5] compared to the test data presented here. The test data shows that the actual optimum is roughly a factor of 2 greater than predicted by the equations.

Per the test series design, several of the tests that were conducted at different layer densities and number of layers were at the same thickness. A141 (60 layers, 1.45 layer $/ \mathrm{mm}$ ), A 139 (40 layers, 0.95 layer $/ \mathrm{mm})$, and A142 (20 layer, 0.52 layer $/ \mathrm{mm}$ ) were all approximately $40 \mathrm{~mm}$ thick. Table 3 shows that as the thermal conductivity decreases with increasing layer density, the overall heat load at constant thickness does the same. This validates the optimal layer density theory. 


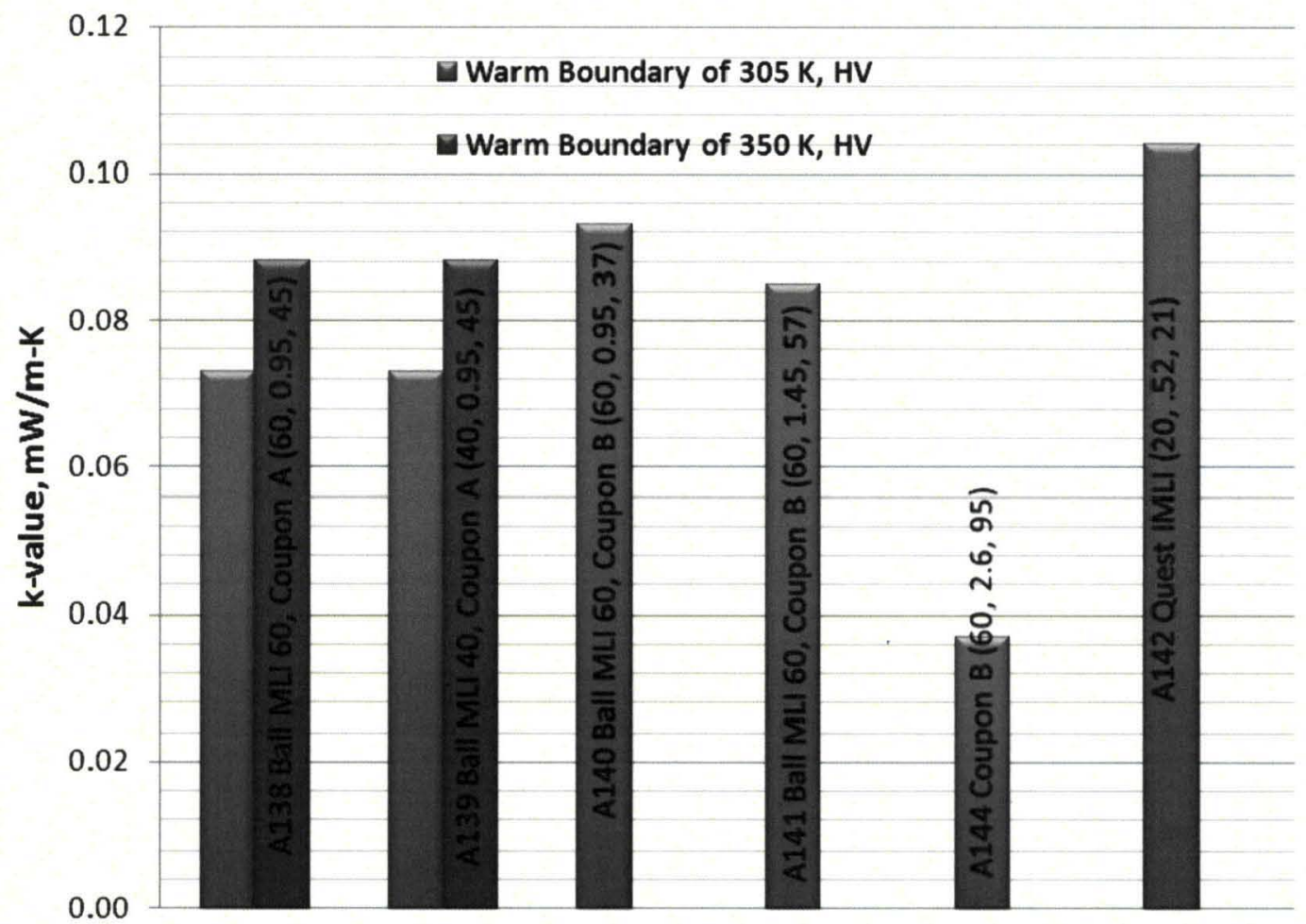

Figure 3: High Vacuum Effective Thermal Conductivity (k-value) for Various MLI Systems

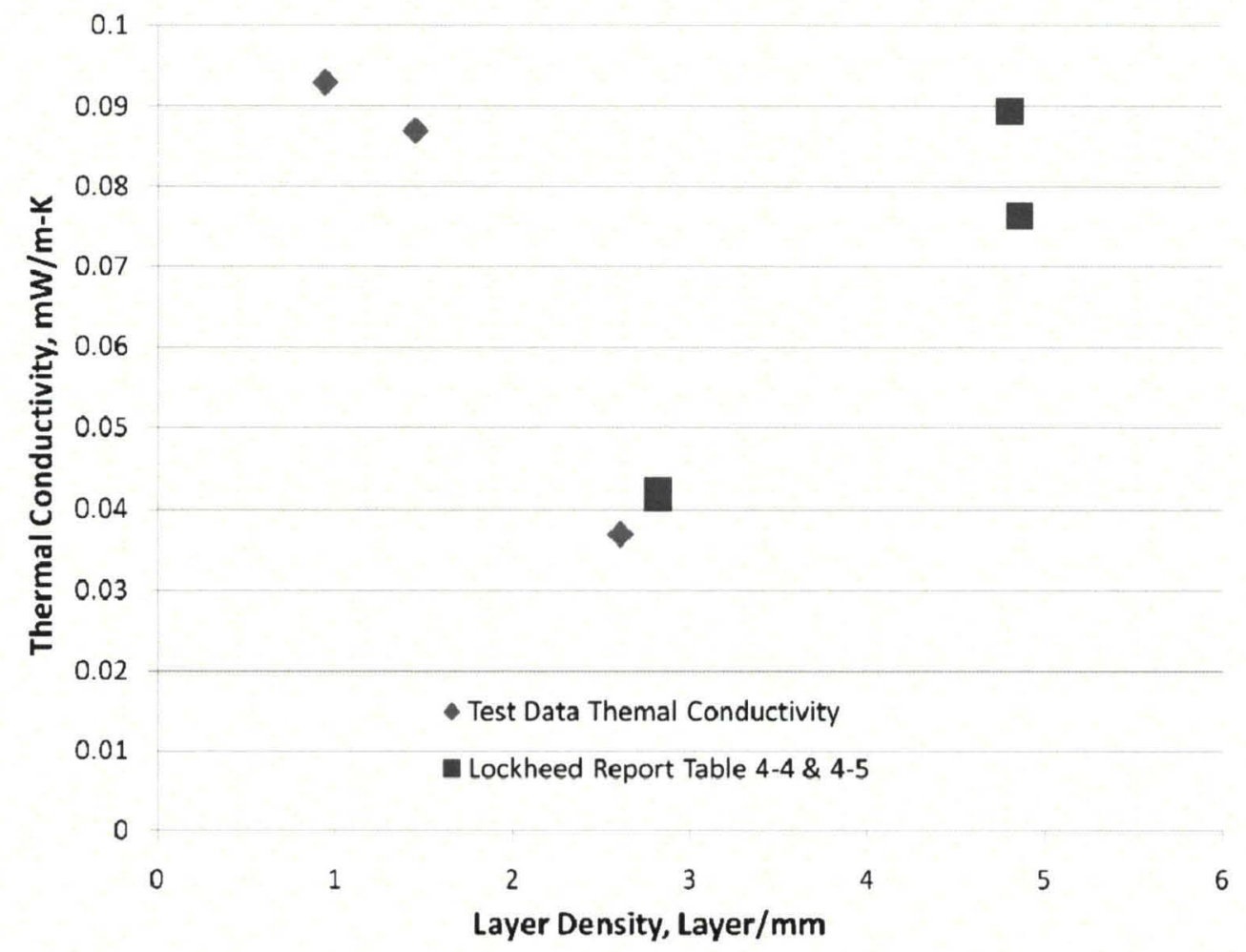

Figure 4: Thermal conductivity test data plotted as a function of layer density [1]

Mass is another important parameter in many applications of high performance insulation. Table 3 also shows the mass and the aerial density of the blanket applied to the entire surface of the calorimeter $\left(0.525 \mathrm{~m}^{2}\right.$ including both guard chambers $)$. While the seam construction is slightly different (causing A139 to be slightly heavier, than the other two, roughly $25 \mathrm{~g} /$ layer), the overall effect is clear in that a direct product of the mass and density for each system shows a tendency towards the lower performing (but lighter) 
system. However, it is not clear that this product is proper for predicting direct mass effects due to increased fluid storage requirements associated with higher heat loads. It does provide an initial look at combining mass and heat load into a single parameter. Further work is required to extend the test data and analysis to a method of optimizing a MLI system for minimum mass.

Table 2: Optimal Layer Densities from Various MLI Equations

\begin{tabular}{cc}
\hline Equation & $\begin{array}{c}\text { Optimal Layer } \\
\text { Density (305 K WBT) }\end{array}$ \\
\hline Lockheed & 1.44 \\
$\begin{array}{c}\text { Modified } \\
\text { Lockheed }\end{array}$ & 1.06 \\
Test Data & $1.5-2.6$ \\
\hline
\end{tabular}

Table 3: Effect of Layer Density on Heat Flux and Mass

\begin{tabular}{|c|c|c|c|}
\hline & $\begin{array}{c}\text { A141 } \\
\text { 60 layers } \\
1.45 \text { layer } / \mathrm{mm} \\
\end{array}$ & $\begin{array}{c}\text { A139 } \\
\text { 40 layers } \\
0.94 \text { layer } / \mathrm{mm} \\
\end{array}$ & $\begin{array}{c}\text { A142 } \\
\text { 20 layers } \\
\text { 0.52 layer/mm }\end{array}$ \\
\hline $\begin{array}{c}\text { Heat Flux } \\
\left(\mathrm{W} / \mathrm{m}^{2}\right)\end{array}$ & $0.367^{*}$ & 0.388 & 0.567 \\
\hline $\begin{array}{c}\text { Mass } \\
\text { (grams) }\end{array}$ & 1565 & 1265 & 526 \\
\hline $\begin{array}{c}\text { Areal Density } \\
\left(\mathrm{kg} / \mathrm{m}^{2}\right)\end{array}$ & 2.98 & 2.41 & 1.00 \\
\hline $\begin{array}{l}\text { Flux Density } \\
\text { Product } \\
\left(\mathbf{W}-\mathbf{k g} / \mathbf{m}^{4}\right)\end{array}$ & 1.09 & 0.94 & 0.57 \\
\hline
\end{tabular}

*Scaled to account for the difference in seam heat loads between coupons A\&B.

\section{CONCLUSIONS}

A series of low layer density MLI tests were completed at the Cryogenics Test Laboratory. The data collected shows that there is indeed an optimal layer density that is higher than the predicted values. 